\title{
Circadian Fitting of Exercise and Intake Bioprocesses: The Secret of Healthy Life
}

\section{Akbar Nikkhah*}

Chief Highly Distinguished Professor, Principal Highly Distinguished Elite-Generating Scientists, Department of Animal Sciences, University of Zanjan, Iran

\begin{abstract}
This paper presents a feasible practice of matching exercise and eating patterns for a healthy and relaxed life style. Quality harmonized rate and extent of eating and physical activity is the only working economical major step to prevent diseases namely cancer towards a quality life. Such harmonies must be established preferably on a circadian basis.
\end{abstract}

\section{Innovative Elaborations}

Human now suffers from devastating diseases and syndromes such as cancer and cardiovascular complexities more than any past time. This unfortunately continues to be exacerbated by other modern factors including obesity, abnormal eating patterns, and severely inadequate exercise. The result is both physical and psychological attacks of pathogens to an essence that used to be naturally oriented. This public article establishes a feasible strategy that aims to harmonize eating and exercise patterns in both extent and rate and preferably on a circadian basis. This public plan is to reduce likelihood of the many health issues in growing the overly modern and artificial human life. Such a practice is a must for the world population before the epidemic obesity, metabolic abnormalities, diabetes, and the resulting related cancers and brain-nerve damages make life more miserable than it has become. The circadian basis of the strategy emphasizes the circadian patterns of life in any form on earth [1]. The science of chronophysiology keeps hope for modulating cell metabolism in animal cells as a model for human [1-3].

Basically, the amount of nutrients intaked must not exceed that outtaked for a body to stay fit and be able to maintain healthy physiology and metabolism [4,5]. Regrettably, however, the modern life has not only increased the amount of nutrients and toxins intake but it has also largely reduced energy and nutrient outtake via exercise and intensive physical activity [6,7]. Intake circadian physiology has been an overlooked specialized and public science [8]. The average body weight of mainly fats has consequently arisen beyond healthy borderlines. This has been worsened by psychological depressions that circularly impair normal eating patterns and unconsciously inactivate sensing a need for substrate burning through physical activity. This unhealthy phenomenon is proposed to be so called as "overmodernization syndrome".

To minimize the chance of getting trapped by the overmodernization syndrome, the circadian rate and extent of physical activity must essentially be equal to those of energy intake to ensure no overconsumption and thus no chance for toxicity and unnecessary deposition. No other way whatsoever can accomplish this. In light of the increasing commercial advertisement on a variety of drugs and chemical agents, public must be increasingly educated to not imprudently rely on such futile drugs and instead exercise adequately. The secret of a successful exercise pattern is not limited to harmonizing nutrient intake and outtake. More importantly, that creates an attentive atmosphere for a modern busy human in which body and psych can be both properly protected against pathogens. The amount of nutrients taken in a $24 \mathrm{~h}$ period should preferably be metabolized and that exceeding daily requirements should be oxidized and burnt the same day to avoid accumulation. The latter increases issues related to toxicity and cell damage due to mismanaged waste $[9,10]$.

\section{Public Implication}

As in the proverb 'never leave today's task on tomorrow', daily eating should be complemented with daily exercise to ensure circadian harmonies between intake and outtake of nutrients. Delaying the harmony till unknown future will make it more challenging and nearly impossible to accomplish.

\section{Acknowledgments}

Thanks go to the Ministry of Science Research and Technology and National Elite Foundation for supporting the author's global programs of optimizing science edification in the new millennium.

\section{References}

1. Nikkhah A (2013) Chronophysiology of ruminant feeding behavior and metabolism: an evolutionary review. Biol Rhythm Res 44: 197-218.

2. Nikkhah A (2012) Time of Feeding an Evolutionary Science, Lap Lambert Publishing $\mathrm{GmbH} \&$ Co. KG, Germany.

3. Nikkhah A (2015) Living on healthy rhythms to overcome cancer: Birth of a public therapeutic science. J Nutr Therap. In Press.

4. Nikkhah A (2015) Demolishing obesity through a circadian public science: An eventual health frontier. Obesity. In Press.

5. Nikkhah A (2015) Harmonizing eating and exercise circadian rhythms for optimal glucose-insulin and vascular physiology. Int J Diabetol Vasc Dis Res. In Press.

6. Nikkhah A (2015) Breast health progress through exercise-driven lactation: A pragmatic bioprocess to prevent cancer. J Bioprocess Biotech 5: e127.

7. Nikkhah A (2015) Optimizing gestation and early life physiology through timing of energy turnover: Bioprocessing of human life. J. Bioprocess Biotech 5: e125.

8. Nikkhah A (2015) Intake circadian physiology: An overlooked public health concern Endocrinol Metab Synd 4: 153.

9. Nikkhah A (2015) Establishing rhythmic regularities in cell physiology: A novel global program to thwart cancer. J Nutr Health Food Eng. In Press.

10. Nikkhah A (2015) Avoid large night meals to stay fit. J Obes Weight Loss Ther 4: e115

*Corresponding author: Akbar Nikkhah, Chief Highly Distinguished Professor, Principal Highly Distinguished Elite-Generating Scientists, Department of Animal Sciences, Faculty of Agricultural Sciences, University of Zanjan, Zanjan, Iran, National Elite Foundation, Tehran, Iran, Tel: +98-24-350-328-01; Fax: +9824-350-332-02; E-mail: nikkhah@znu.ac.ir

Received March 15, 2015; Accepted March 17, 2015; Published March 20, 2015

Citation: Nikkhah A (2015) Circadian Fitting of Exercise and Intake Bioprocesses: The Secret of Healthy Life. J Bioprocess Biotech 5: e129 doi:10.4172/2155$9821.1000 \mathrm{e} 129$

Copyright: @ 2015 Nikkhah A. This is an open-access article distributed under the terms of the Creative Commons Attribution License, which permits unrestricted use, distribution, and reproduction in any medium, provided the original author and source are credited. 